\title{
Pan-American Trypanosoma (Megatrypanum) perronei sp. $n$. in white-tailed deer (Odocoileus virginianus) and its deer ked Lipoptena mazamae: morphological, developmental and phylogeographical characterisation
}

Herakles Antonio Garcia ( $\nabla$ heraklesantonio@gmail.com )

University of Sao Paulo https://orcid.org/0000-0002-1579-2405

Alexander P. Blanco

Universidad Central de Venezuela Facultad de Ciencias Veterinarias

Adriana C. Rodrigues

Universidade de Sao Paulo

Carla M. Rodrigues

Universidade de Sao Paulo

Carmen S. A. Takata

Universidade de Sao Paulo

Marta Campaner

Universidade de Sao Paulo

Erney P. Camargo

Universidade de Sao Paulo

Marta M. G. Teixeira

Universidade de Sao Paulo

\section{Research}

Keywords: Cervidae, deer keds, phylogeny, taxonomy, Great American Interchange, host-parasite restriction

Posted Date: December 18th, 2019

DOI: https://doi.org/10.21203/rs.2.19170/v1

License: (c) (1) This work is licensed under a Creative Commons Attribution 4.0 International License.

Read Full License 


\section{Abstract}

Background: The subgenus Megatrypanum comprises trypanosomes of cervids and bovids from around the world. Here, Odocoileus virginianus (white-tailed deer = WTD) and its ectoparasite, the deer ked Lipoptena mazamae (hippoboscid fly), were surveyed for trypanosomes in Venezuela.

Results: Haemoculturing unveiled $20 \%$ infected WTD, while $47 \%(7 / 15)$ of blood samples and $38 \%$ $(11 / 29)$ of ked guts tested positive for the Megatrypanum-specific TthCATL-PCR. CATL and SSU rRNA sequences uncovered a single species of trypanosome. Phylogeny based on SSU rRNA and gGAPDH sequences tightly cluster WTD trypanosomes from Venezuela and the USA, which were strongly supported as geographical variants of the herein described Trypanosoma (Megatrypanum) perroneisp. $\mathrm{n}$. In our analyses, T. perronei was closest to T. sp. D30 of fallow deer (Germany), both nested into Tthll alongside other trypanosomes of cervids (North American elks and European fallow, red and sika deer), and bovids (cattle, antelopes and sheep). Insights into T. perronei life cycle were obtained from early haemocultures of deer blood and co-culture with mammalian and insect cells showing flagellates resembling Megatrypanum trypanosomes previously reported in deer blood, and deer ked guts. For the first time, a trypanosome from a cervid was cultured and phylogenetically and morphologically (light and electron microscopy) characterised.

Conclusions: In the analyses based on SSU rRNA, gGAPDH, CATL and ITS rDNA sequences, neither cervids nor bovids trypanosomes were monophyletic but intertwined within Tthl and Tthll major phylogenetic lineages. One host species can harbour more than one species/genotype of trypanosomes, but each trypanosome species/genotype was found in a single host species or in phylogenetically related hosts. Molecular evidence that L. mazamae may transmit T. perronei suggests important evolutionary constraints making tight the tripartite $T$. perronei-WTD-deer ked association. In a plausible evolutionary scenario, T. perronei entered South America with North American WTD at the Pliocene-Pleistocene boundary following the closure of the Panama Isthmus.

\section{Background}

Trypanosomes of the subgenus Megatrypanum are distributed worldwide in bovids and cervids. Cervidae comprises 55 species widespread in Eurasia and America of two subfamilies: Cervinae, which comprises mostly deer from Eurasia of the genera Axis, Dama, Elaphurus, Rucervus, Rusa and Cervus (the only genus also present in North America); and Capreolinae, which comprises deer from Eurasia (Capreolus), Eurasia and North America (Alces, Rangifer), and deer endemic to the Americas (Odocoileus) or restricted to South America (Blastocerus, Hippocamelus, Mazama, Ozotoceros, Pudu) [1].

In North American cervids, Megatrypanum trypanosomes have been reported in caribou (Rangifer tarandus caribou) [2, 3], red deer (Cervus elaphus) [4], roe deer (Capreolus capreolus) [5-7], reindeer (Rangifer tarandus) [8], mule deer (Odocoileus hemionus) [3, 9], moose (Alces alces) [10], white-tailed deer (WTD) (Odocoileus virginianus) and elk (Cervus canadensis) [3, 11, 12]. In Europe, Megatrypanum 
trypanosomes have been described in fallow deer (Cervus dama), red deer and roe deer in Germany [6], reindeer and moose in Sweden [13], roe deer in Poland [14], and red deer in Croatia [15]. In Asia, a Megatrypanum trypanosome was reported in Cervus nippon, the Japanese sika deer [16]. Megatrypanum trypanosomes are generally non-pathogenic to domestic and wild ruminants including deer [8].

Contrasting with molecularly characterised Megatrypanum trypanosomes of deer from across the North America and Europe (Sweden, Germany, Croatia and Poland) [12-15], reports of these trypanosomes in South American cervids are limited to the morphology of blood trypomastigotes in WTD, black-tailed deer (Odocoileus hemionus columbianus) and brown brocket deer (Mazama guasubira) in Colombia [17, 18], and brocket deer in Argentina and Brazil [19, 20].

Traditionally, the large and broad shape of blood trypomastigotes is the main taxonomic criterion of the subgenus Megatrypanum (type species T. theileri reported in Bos taurus), whereas species identification relies on data about host restriction provided by field, and cross-experimental infections [13,21,22]. This subgenus was revised by Hoare [21] to accommodate trypanosomes of artiodactyls, bats, rodents, nonhuman primates and marsupials, excluding trypanosomes of non-mammalian hosts formerly included in this subgenus. However, molecular phylogeny revalidated this subgenus as a monophyletic assemblage comprising the type/species T. theileri of cattle and virtually morphologically indistinguishable trypanosomes from bovids and cervids, and excluding non-ruminant trypanosomes, even their closest relatives forming the Trypanosoma cyclops sister clade [15, 23-25]. Although T. theileri was never observed in blood of hosts other than ruminants, PCR-surveys detected DNA of this trypanosome in bats [26], and in one chimpanzee [27].

Currently, there are three named species of deer Megatrypanum trypanosomes, all relying just on morphology and host species of origin: Trypanosoma mazamarum in brocket deer from Argentina [19]; Trypanosoma cervi in elks from the USA [28]; and Trypanosoma stefanskii in roe deer from Poland [14]. Molecular studies have uncovered different species/genotypes of Megatrypanum trypanosomes in WTD and elks in the USA [12], red deer in Croatia [15], sika deer in Japan [16], and the invader sika deer plus wisent (European bison), red deer and fallow deer in Poland [29].

Megatrypanum trypanosomes are thought to be cyclically transmitted by tabanid and hippoboscid flies. Trypanosomes similar to T. cervi have been reported in tabanids (deer flies) in the USA, Germany, Russia and Poland [22, 29-31]. Tabanids harbouring trypanosomes of bovids have been reported in North America [32], South America [24, 33], and Africa [34-36]. The sheep ked Melophagus ovinus transmit Trypanosoma melophagium exclusive of sheep $[15,21,37]$ while Trypanosoma theodori of goats is transmitted by Lipoptena caprae [21]. The finding of trypanosomes in guts of Lipoptena cervi taken from red deer suggests that hippoboscid flies may transmit deer trypanosomes [38]. However, molecular comparisons of Megatrypanum trypanosomes from deer blood and keds are still lacking.

Comprehensive molecular data on Megatrypanum trypanosomes from wild and domestic ruminants and the proper identification of vectors are essential to understand their evolution, species richness, phylogenetic relationships, range of vertebrate hosts, vectors, and geographical distribution. In the 
present study, we describe a new species of Megatrypanum in WTD and its deer ked and hypothesise its probable life cycle and evolutionary history by integrating morphological, culture behaviour, biological, and phylogeographical data.

\section{Methods}

\section{Study area, deer blood and ked collection, and DNA preparation}

A total of 75 WTDs were captured at the Anzoátegui state, municipality of Simón Bolívar, an important livestock breeding area at north-eastern Venezuela (N1007'08.95", W64 $\left.38^{\prime} 23.80^{\prime \prime}\right)$ (Fig. 1), where the mean annual temperature is $25^{\circ} \mathrm{C}\left(21.8^{\circ} \mathrm{C}-32.2^{\circ} \mathrm{C}\right)$ and rainfall is below $1000 \mathrm{~mm}$, with a dry season from December to April. The captured WTDs (Fig. 2) were kept in quarantine prior to their introduction into a protected reserve. Chemical immobilization and anaesthesia were performed with a combination of 10 $\mathrm{mg} / \mathrm{kg}$ ketamine and $0.6 \mathrm{mg} / \mathrm{kg}$ xylazine intramuscularly and reverted with $0.2 \mathrm{mg} / \mathrm{kg}$ of yohimbine intravenously. Anesthetized deer were examined to record heart and breathing frequency rates and temperature. Institutional and National guidelines for the care and use of wild animals were followed. Deer handling were performed in accordance with the protocol approved by the MINEC from Venezuela 2013-154125.

Blood samples were obtained via jugular vein using tubes with EDTA and aliquots $(\sim 500 \mu \mathrm{l})$ of blood were preserved in $99.5 \%$ ethanol $(\mathrm{v} / \mathrm{v})$, incubated overnight in $250-500 \mu \mathrm{l}$ of lysis buffer (20mM EDTA; $50 \mathrm{mM}$ Tris-HCL; $117 \mathrm{mM} \mathrm{NaCl} ; 1 \%$ SDS; $10 \mathrm{mg} / \mathrm{ml}$ Proteinase K), precipitated with 400-800 $\mu \mathrm{l}$ ammonium acetate (4M), and centrifuged (10 min at 20,000 g). Then, DNA was precipitated with ethanol, dried at room temperature and resuspended in TE (Tris-EDTA). Deer keds (Fig. 2) were removed from the WTDs, preserved in ethanol, and identified by morphological parameters [39], and CO/barcoding using DNA obtained from the gut contents of keds as described previously for tsetse flies [40]. Due to limited field facilities, the guts of deer keds were not examined by microscopy or culturing.

\section{Isolation of deer trypanosomes by hemoculturing}

Deer blood samples were examined by microhematocrit, Giemsa-stained blood smears and hemoculturing $[15,24,25]$. Aliquots $(\sim 200 \mu \mathrm{l})$ of blood were used for hemoculturing in medium consisting of blood agar base containing 15\% rabbit blood as a solid phase and an overlay of liquid Liver Infusion Tryptose medium with $10 \% \mathrm{FBS}$, and incubated at $25^{\circ} \mathrm{C}[23,24]$. Positive haemocultures were transferred to culture flasks containing a monolayer of insect cell (Hi-5 from Trichoplusia $n i)$ in TC100 medium (= Grace's medium) with $10 \%$ FBS and incubated at $25^{\circ} \mathrm{C}$ [41]. Cultures were expanded in TC100 for DNA preparation and cryopreservation at the Trypanosomatid Culture Collection (TCC) of the Department of Parasitology, University of São Paulo (USP), São Paulo, Brazil.

\section{Trypanosome diagnosis in deer blood and keds and network of CATL sequences}


The Megatrypanum-specific TthCATL-PCR based on Cathepsin-L (CATL) sequences was used for surveys in deer blood and ked guts as described previously [25,42]. The cdCATL sequences (274 bp) of trypanosomes amplified by TthCATL-PCR were cloned and sequences determined were aligned with those of other Megatrypanum trypanosomes (GenBank, Supplementary Table S1), and used for network inferences [25,42]. Sequences of the whole CATL catalytic domain (477 bp) were determined for the isolate TCC2268 $[25,42]$.

\section{Phylogenetic analysis of SSU rRNA, gGAPDH and ITS rDNA sequences}

DNA from cultured trypanosomes extracted by the phenol-chloroform method was used for PCR amplification of sequences from the variable V7V8 region ( 728 bp) or entire (2142 bp) SSU rRNA gene, gGAPDH (glycosomal glyceraldehyde 3-phosphate dehydrogenase) ( 847 bp) gene and ITS1 rDNA ( 233 bp) sequences $[24,25,43]$. PCR products were purified, cloned and sequences of 5-10 clones from each amplicon were determined and aligned with sequences obtained from the GenBank using the Clustal $X$ program [44]. We created the following alignments: a-V7V8 SSU rRNA sequences herein determined and available in GenBank of Megatrypanum trypanosomes, b- concatenated V7V8 SSU rRNA and gGAPDH sequences ( 1575 bp) of Megatrypanum trypanosomes from deer, cattle, water buffalo, antelopes and sheep; trypanosomes of other subgenera were also included, and other trypanosomatids were used as outgroups, c-ITS1 rDNA sequences of Megatrypanum trypanosomes. Phylogenies were inferred using parsimony $(\mathbf{P})$, maximum likelihood $(\mathbf{M L})$ and Bayesian inferences $(\mathbf{B I})$. $\mathbf{P}$ and bootstrap analyses were carried out using PAUP 4.0b10 [45] with 500 replicates of random addition sequences followed by branch swapping (RAS-TBR). ML was performed using RAxML-VI-HPC v.2.2.3 [46] with tree searches using GTR model with gamma-distributed rate variation across sites and proportion of invariable sites (GTRGAMMA model), and 500 maximum parsimony starting trees; the model parameters were estimated in RAXML for the duration of the tree search. Nodal supports were estimated with 500 bootstrap replicates in RAxML using GTRGAMMA and P starting trees. BI was performed in MrBayes v3.1.2 [47] with GTRGAMMA, and the first $25 \%$ of the trees from 1 million generations were discarded as burn-in. Sequences of ITS1 rDNA were employed for network split decomposition using the Neighbor-Net method with Kimura 2-parameter implemented in Splits Tree4 V4.10 [48]. Internode support was estimated by 500 bootstrap replicates using the same parameters optimized for network inferences.

Trypanosomes included in our analyses, and their host species, geographical origins and GenBank accession numbers of DNA sequences are detailed in the Supplementary Tables S1-S4 (S1, CATL sequences; S2, SSU rRNA; S3, gGAPDH; S4, ITS1 rDNA). All DNA sequences here determined were deposited in GenBank.

\section{Growth behaviour and light and electron microscopy of trypanosomes co-cultivated with insect and mammalian cells}

The isolate TCC2268 was co-cultivated with a monolayer of Hi-5 insect cells (TC100 medium) and flagellates from stationary cultures were seeded on monolayers of monkey LLC-MK ${ }_{2}$ cells, cultivated at 
$37^{\circ} \mathrm{C}$ with $5 \% \mathrm{CO} 2$, and intracellular parasites were investigated according to [49]. Both cultures were examined daily in an inverted microscopy, and supernatants of 2, 5, 7 and 10 days of culture were smeared in glass slides, fixed with methanol, and stained by Giemsa for light microscopy.

Both SEM and TEM were performed as detailed described in [41]. For scanning electron microscopy (SEM), trypanosomes fixed in glutaraldehyde were adhered to poly-L-lysine-coated coverslips and processed for observation on a FEI Quanta 250 (FEI Company, Hillsboro, United States) microscope. For transmission electron microscopy (TEM), trypanosomes were fixed in glutaraldehyde, post-fixed with osmium tetroxide and embedded in Spurr resin. Ultrathin sections were stained with uranyl acetate and lead citrate and examined with a LEO 906E microscope (Zeiss, Jena, Germany). Images were captured by a CCD camera MegaView III.

\section{Results And Discussion}

\section{White-tailed deer and deer keds harbour Megatrypanum trypanosomes uncovered by TthCATL-PCR}

Overall, 15 WTDs including 9 males ( 5 juveniles and 4 adults) and 6 juvenile females captured were clinically healthy, showing normal values of heart frequency ( 44 to 128 , mean of 76 , beats $/ \mathrm{min}$ ), breathing frequency ( 18 to 48 , mean of 34 , breaths/min), and body temperature $\left(35.4^{\circ} \mathrm{C}\right.$ to $40.2^{\circ} \mathrm{C}$, mean of $37.4^{\circ} \mathrm{C}$ ). Inspection of WTDs (Fig. 2) for ectoparasites revealed an abundance of deer keds in $~ 73 \%$ $(11 / 15)$ of them, mainly in the ventral, inner legs, and inguinal regions of the WTDs. No skin or fur damage was observed in ked-infested WTDs. Twenty-nine keds preserved in ethanol were identified morphologically as Lipoptena mazamae (Fig. 2) [39] and confirmed by COIDNA barcoding (GenBank: MN756795).

Microscopy of Giemsa-stained blood smears and the microhematocrit technique were unable to detect trypanosomes in blood of the 15 WTDs examined. However, haemoculturing (Fig. 2) yielded a trypanosome infection rate of $20 \%$ (three positive cultures), and one culture (TCC2268) was established and cryopreserved. These findings are consistent with very low parasitaemia but positive haemocultures as previously reported for other Megatrypanum trypanosomes [23,25]. The Megatrypanum-specific assay, TthCATL-PCR, was employed aiming at the detection of trypanosomes in blood samples from WTD and in gut contents from the deer keds. PCRs were positive for 7 out of 15 WTDs ( 47\%), and 11 out of 29 deer keds $(\sim 38 \%)$, including keds from the three WTD positive by haemoculturing.

\section{Characterisation of trypanosomes from blood and keds of white-tailed deer using CATL sequences}

CATL DNA sequences (274 bp) obtained by TthCATL-PCR from blood samples and culture (isolate TCC2268) of WTD and deer keds share highest similarity with sequences of Megatrypanum trypanosomes. Sequences herein determined were aligned with those of other Megatrypanum trypanosomes (GenBank) and used to infer their genetic relatedness. Trypanosome sequences obtained from deer keds were virtually identical to those obtained from WTD blood (TCC2268), indicating that they belong to a single trypanosome species. 
Network inferences of 100 CATL sequences of 274 bp, amplified by TthCATL-PCR (Fig. 3) or 53 larger CATL sequences of $477 \mathrm{bp}$ (data not shown) generated highly similar networks. A divergence of $\sim 2.0 \%$ in the small fragment of CATL sequences separated TCC2268 from T. sp. D30. Even though originating from different continents, these two deer isolates were much more related to each other than to trypanosomes from bovids (cattle, buffalo, sheep and antelopes), even those from Venezuelan cattle and buffalo [25]. TCC2268 and T. sp. D30 were assigned to close but different genotypes, Tthll H (which includes CATL sequences from the deer keds) and Tthll C, respectively. TCC2268 diverged by $5.3 \%$ from $T$. melophagium (Tthll D) and by 3.3\% from T. theileri of cattle nested into Tthll (Fig. 3B).

Although useful for assessment of genetic diversity [42,50-52], the small polymorphism detected in short CATL sequences generated by TthCATL-PCR may be insufficient to discriminate reliable lineages and genotypes, therefore, the description of novel genotypes must be supported by additional markers including conserved (SSU rRNA and gGAPDH), and polymorphic (ITS rDNA and SL rRNA) sequences $[15,25,42,43,50,53]$.

\section{Barcoding of deer trypanosomes through SSU rRNA sequences revealed a new Megatrypanum trypanosome in white-tailed deer}

Our comparative analysis of V7V8 SSU rRNA barcodes comprised Megatrypanum trypanosomes from cervids (Venezuela, Germany, Poland, Croatia, Japan, USA), and a large data set of trypanosome sequences from bovids including: cattle (Brazil, Venezuela, Argentina, Colombia, Germany, Poland, Croatia, UK, Japan, USA), water buffaloes (Venezuela, Colombia, Brazil), antelopes (Cameroon, Tanzania), and bison (Poland). In addition, our analyses included sequences of Megatrypanum trypanosomes from the guts of tabanids (Brazil, Africa, Russia), hippoboscids (Croatia, Scotland), tsetse flies (Africa) and sand flies (Italy) (Fig. 4; Supplementary Table S2). SSU rRNA barcodes corroborated the distribution of cervid and bovid trypanosomes in both Tthl and Tthll lineages, whereas the branching patterns intralineages could not be resolved using exclusively these highly conserved sequences (Fig. 4). In addition, two sequences of an elk (elk 317, GenBank JX178200-201) from the USA diverged by relevant and equidistant genetic distances from Tthl ( 3.0\% divergence) and Tthll ( 3.1\%), apparently representing a new lineage of Megatrypanum (Fig. 4).

SSU rRNA sequences of the Venezuelan isolate WTD TCC2268 was highly similar (99.7\%) to that of the isolate WTD A3 from the USA, both sharing $99.5 \%$ similarity with $T$. sp. D30 of fallow deer from Germany. Besides these three deer trypanosomes, Tthll comprised Trypanosoma cf. cervi from North American elk (elk328), and isolates of red deer (Cel34), fallow deer (DdP18) and sika deer (Cn1) from Poland. In addition, Tthll included trypanosomes from African antelopes and T. melophagium of sheep, all clustering close to the trypanosomes of deer, whereas trypanosomes of cattle from North and South America, Europe and Asia formed a more separated cluster (Fig. 4). Trypanosomes from these European deer nested into Tthll diverged from TCC2268 by $0.3 \%-0.6 \%$ in highly conserved SSU rRNA sequences. For comparison, TCC2268 diverged by just $0.6 \%$ from the reference $T$. theileri TREU124 of cattle, thus 
reinforcing that these sequences are too conserved to clearly resolve the relationships of the recently diversified Megatrypanum trypanosomes. Regarding possible vectors, trypanosome sequences obtained from the guts of Brazilian, Poland and Russian tabanids and Central African Republic tsetse flies were all assigned to both Tthl and Tthll lineages $[24,29,36]$.

The lineage Tthl also harboured trypanosomes (misclassified) referred to as Trypanosoma cf. cervi identified in WTDs (WTD A1, A5, A21, A148, NL15) and elks (elk142, elk328, elk416, elk421) from the USA [12], and isolates referred to as T. cervi from Poland red deer (Cel14St), fallow deer (DdP287) and tabanids (Fig. 4). The trypanosome (TSD1) from the Japanese sika deer [16] is the deer trypanosome more genetically distant ( 1.4\% sequence divergence) from the isolate TCC2268 (Fig. 4). In addition, this lineage also comprises $T$. theileri of cattle from South America, Japan and the USA, and T. theileritike trypanosomes of South American water buffalo and Polish wisent [24,25,29].

\section{Phylogeny based on concatenated SSU rRNA and gGAPDH genes support the independent species status for the new trypanosome from Venezuelan white-tailed deer in the subgenus Megatrypanum}

It was previously demonstrated that gGAPDH sequences are generally more variable than SSU rRNA sequences, thus being more suitable for a better differentiation between closely related trypanosomes such as those of the subgenus Megatrypanum [15,24,25]. Corroborating results using SSU rRNA sequences, gGAPDH sequence from the isolate WTD TCC2268 was closest to T. sp. D30 ( 2.2\% sequence divergence), and more similar to T. melophagium and trypanosomes of antelopes, all clustering together. Cattle isolates formed other group within Tthll, separated from WTD TCC2268 by an average of $\sim 4.4 \%$ sequence divergence.

Here, gGAPDH sequences of TCC2268 were compared with available sequences from species/genotypes of Megatrypanum and concatenated with SSU rRNA sequences. The inferred phylogeny (Fig. 5) displayed a highly congruent topology compared with those of independent SSU rRNA (Fig. 4) or gGAPDH sequences (data not shown). Together, phylogenetic positioning and genetic distances of WTD TCC2268 from other phylogenetically validated species of Megatrypanum allowed for the description of this new isolate as a novel species herein designated Trypanosoma (Megatrypanum) perronei sp. n. Unfortunately, most trypanosomes from cervids have been known merely by partial SSU rRNA sequences such as those reported from elk and WTD from the USA, and deer isolates from Japan and Poland included in our previous SSU rRNA analysis (Fig. 4). Results obtained in the present study are congruent with previous studies using SSU rRNA, gGAPDH, CATL and ITS rDNA sequences $[15,24,25,42,50,53]$.

\section{Small polymorphism between ITS1 rDNA sequences of $T$. perronei sp. $n$. of white-tailed deer from Venezuela and the USA}

To better understand the relatedness of $T$. perronei sp. n. with its closely related trypanosomes of deer from the USA and Germany, we compared ITS1 rDNA sequences, which are much more polymorphic than 
SSU rRNA and gGAPDH sequences. A comprehensive analysis of 122 ITS1 rDNA sequences from Megatrypanum trypanosomes (Fig. 6) was carried out including sequences of trypanosomes from a range of deer species and geographic origin: WTD TCC2268 from Venezuela ( $n=2$ sequences); WTD A3 $(n=2)$, WTD A1 $(n=2)$, WTD A21 $(n=3)$, WTD NL15 $(n=3)$, elk $416(n=1)$, elk $142(n=2)$, elk $421(n=$ 1), and elk $328(n=1)$ from the USA; TSD1 $(n=1)$ from Japanese sika deer; TC2 $(n=1)$ from Croatian red deer; and T. sp. D30 from German fallow deer $(n=2)$. These sequences were aligned with those from bovid trypanosomes: T. theileri of cattle (29 sequences of Tthl and 37 of Tthll lineage); T. theileritike of water buffalo $(n=13)$; T. melophagium of sheep ked; and trypanosomes of the antelopes $(n=14)$ sitatunga, duiker and puku.

Confirming previous studies, ITS1 rDNA sequences of Megatrypanum trypanosomes were distributed in the Tthl and Tthll lineages (Fig. 6) regardless of originating from bovids or cervids; thus, corroborating data from this (Figs 3-5) and previous studies [12,15,24,25,53]. Our analysis supported 6 genotypes of Tthl (IA-IF) and 9 of TthII (IIA-II I) (Fig. 6). ITS1 rDNA sequences of T. perronei from Venezuela and the USA shared highly similar sequences ( $\sim 0.6 \%$ divergence), and were tightly clustered together supporting the genotype Tth II $\mathrm{H}$. Trypanosomes from European cervids assigned to the lineage Tth II $\mathrm{C}$ were the German T. sp. D30 of fallow deer [12,25] that clustered with the highly similar Croatian trypanosome of red deer [15], and they diverged by $\sim 17 \%$ from T. perronei. Regarding the relationship between cervid and bovid trypanosomes, ITS1 rDNA sequences of T. melophagium of sheep diverged only by $\sim 18 \%$ from $T$. perronei while divergences above $24 \%$ separated $T$. perronei from trypanosomes of cattle (Tthll $A$ and Tthll B) and African antelopes (Tthll F, G, E, I) [25].

Interestingly, ITS1 rDNA sequence of a trypanosome obtained from the gut of an Italian sand fly [54] was virtually identical to those of $T$. sp. D30 from Germany [22]. As expected, deer trypanosomes of Tthl diverged from T. perronei by remarkable divergences in ITS rDNA (Fig. 6): 46\% from both TthI D (WTD and elk) and Tthl E (elk), which are genotypes identified in deer sympatric with the WTD from which $T$. perronei sp. n. (isolate WTD A3) was obtained in the USA [12]. As we showed with other molecular markers, the greatest distances of ITS rDNA ( 49\%) among deer trypanosomes was between T. perronei and the trypanosome from Japanese sika deer (Tthl F).

\section{Host-parasite-vector relationships and evolutionary history of cervid trypanosomes}

Although host specificity of Megatrypanum trypanosomes remains to be clearly demonstrated, our findings provide additional support for relevant host-parasite-vector association in the evolution of these trypanosomes. Species diversification was likely shaped by evolutionary constraints exerted by ruminant hosts. In addition, vectors may be also involved in trypanosome host-restriction because deer flies (tabanids) and deer keds (hippoboscids) are highly associated to their cervid hosts. In agreement with this hypothetical evolutionary scenario, we demonstrated that deer keds taken from WTD exclusively harboured $T$. perronei sp. n., corroborating a previous suggestion that these flies can transmit, cyclically and/or mechanically, trypanosomes to cervids [38]. L. mazamae occurs from south-eastern USA to South 
America [39,55], and is tightly linked to WTD, although this ked can eventually jump to phylogenetically close deer species [39]. Deer flies, which have been experimentally proven to transmit deer trypanosomes, and deer keds have been implicated as vectors of cervid trypanosomes [21,29,31,36,38,56,57]. Recent studies report on DNA from deer trypanosomes in guts of sand flies and culicids [54,58], but their roles as vectors remains to be investigated.

Trypanosome cross-infections of cervids and bovids have not been confirmed experimentally or by molecular epidemiology $[8,12,15,21,24,25,33,53,59]$. In Venezuela, we found WTD infected with T. perronei sp. n. while sympatric cattle and water buffalo were found infected with $T$. theileri and $T$. theilerilike, respectively [25]. Japanese sika deer were found infected exclusively with the $T$. sp. TSD1, whereas sympatric cattle were infected with $T$. theileri of both Tthl and Tthll lineages [53]. Deer, cattle and sheep harboured host-specific trypanosomes in Croatia [15]. All these findings, coupled with data herein reported, provide strong evidence that Megatrypanum trypanosomes exhibit a narrow host range or even host specificity. Each trypanosome species/genotypes were found in a single host species or in closely phylogenetically related hosts, those found in cervids were never detected in bovids although one host species can harbour trypanosomes of more than one species or genotype [12,23-25,53]. To date, reports of elks and WTD sharing trypanosome genotype [12] relied merely on DNA detection, and genuine infections remain to be demonstrated. Reports of T. cervi, originally in an elk [28], and subsequently in a range of deer including WTD, wapitis [28], mule deer [9], moose [10] and reindeer in the USA [8], and in European fallow, roe and red deer [6] must be molecularly confirmed.

It has been demonstrated by isoenzyme and karyotype analyses that the trypanosome found in Swedish reindeer differ from those found in moose, and both differed from cattle isolates, despite all these animals living in sympatry [13]. Similarly, data from zymodemes suggested the existence of different species of Megatrypanum infecting distinct species of deer and cattle in Germany [59]. The isolates of $T$. perronei sp. n. from Venezuela and the USA are closely related, but not identical. Interestingly, T. perronei $\mathrm{sp}$. n. is more related to deer trypanosomes from Germany, Croatia, Poland and Russia, all nested into Tthll lineage $[15,29,31,54]$, than to trypanosomes found in sympatric WTD and elks (USA) nested into Tthl, a lineage also harbouring a trypanosome of Japanese sika deer [12,16].

Our findings agreed with multiple and relatively recent crossings of the Bering Strait by cervids infected with Megatrypanum trypanosomes reaching North America from Eurasia, and from these regions dispersing through the world. Altogether, deer-trypanosome-vector associations and phylogeography support a plausible evolutionary scenario where WTD infected with the ancestor of $T$. perronei sp. n., likely infested by its tightly linked ectoparasite L. mazamae, were introduced from North America into South America through the Panama Isthmus, reaching this continent at the Pliocene-Pleistocene boundary $[1,60]$. Cervidae originated in Asia between 7.7 and 9.6 mya, and according to fossil records, deer did not cross the Bering Land Bridge to North America before 4.2 to 5.7 mya [60]. South American cervids are thought to have originated from at least two invasion events by North American deer: firstly, by the common ancestor of all deer species endemic of South America during the Great American Interchange at the Early Pliocene ( 3 mya); and more recently ( 1.5 mya) only by WTD at the Pliocene-Pleistocene 
boundary $[1,60]$. Concordant with our data on Megatrypanum trypanosomes, host-helminth assemblages were also associated with an early dispersion of cervids and bovids from Eurasia into North America and then into the Neotropics [61]. Also supporting the recent dispersion of cervids and their parasites, Plasmodium sp. from the South American pampas deer (Ozotoceros bezoarticus) is closely related to Plasmodium odocoilei of North American WTD, and these two species are estimated to have diverged just by $0.3-0.9$ mya [62].

\section{Growth behaviour and developmental forms of $T$. perronei sp. $\mathrm{n}$. in early haemocultures and co-cultivated with insect and mammalian cells examined by light and scanning electron microscopy}

In early (7-10 days) haemocultures of WTD blood, live flagellates (phase microscopy) exhibited a few trypomastigotes with large body length, pointed posterior ends and noticeable undulating membrane, alongside large transition forms between trypo- and epimastigote forms, and dividing epimastigotes (Fig. 2A). Flagellates of $T$. perronei sp. $\mathrm{n}$. from early haemocultures seeded on monolayers of insect cell (Hi-5), at $25^{\circ} \mathrm{C}$, initially formed clumps of small and rounded forms attached to insect cell membranes; these forms increased in length to became epimastigotes that remained adhered by their flagella forming rosettes until released into the supernatant of cultures (Fig. 2B). The developmental forms of T. perronei sp. n. co-cultivated with Hi-5 insect cells very much resembled those reported for T. (Megatrypanum) spp. in the guts of the ked L. cervi taken from red deer [38] and T. melophagium adhered to the cells of gut walls of the sheep keds [15,21].

Epimastigotes of $T$. perronei sp. $\mathrm{n}$. in log phase Hi- 5 cultures ( 5 days) multiply intensively attached by their flagella forming large rosettes (Fig. 7a), which initially remained adhered to the insect cells and afterwards are released in the supernatant, where free epimastigotes became progressively abundant (Fig. 7a,b). Giemsa-stained epimastigotes showed the rounded kinetoplast adjacent and lateral to the central nucleus with an almost imperceptible undulant membrane, and a long free flagellum (Fig. 7a,b). In mid-log cultures (7 days), most epimastigotes became longer and thinner with a pointed posterior extremity (Fig. 7b). Stationary phase cultures (10 days) of T. perronei sp. n. exhibited variable forms, all with a long free flagellum, including some wider epimastigotes exhibiting more preeminent undulant membranes (Fig. 7c). Some forms became progressively shortened in their posterior ends giving origin to blunted forms (indicated by arrow heads) during the differentiation of epi- to trypomastigotes (Fig. 7 b,c) and, finally, to 'rounded' forms with a long flagellum (Fig. 7b,c), which most likely represented metacyclic trypomastigote forms (Fig. 7d). In contrast with the slow movement of long epimastigotes, these "rounded" forms are highly mobile, and resemble metacyclic trypomastigotes of $T$. theileri described previously in the guts of tabanid flies and stationary cultures [57]. Overall, initial co-cultivation of $T$. perroneisp. $\mathrm{n}$. with insect cells, at $25^{\circ} \mathrm{C}$, showed flagellates resembling those of Trypanosoma (Megatrypanum) spp. present in the guts of L. cervi, the Old-World deer ked taken from red deer [38].

Scanning electron microscopy (SEM) of the mid-log cultures (7 days) of T. perronei sp. $\mathrm{n}$. in Hi-5 cultures showed flagellates of variable length and shape (Fig. 7e-j): slender epimastigotes without a noticeable undulant membrane (Fig. 7e) become broader epimastigotes exhibiting a conspicuous undulant 
membrane easily detectable by SEM (Fig. 7f,i,j). Following the differentiation from epi- to metacyclic trypomastigotes, a range of transition forms (indicated by arrows heads) were observed, including flagellates with a pointed posterior end and swollen central region (Fig. 7f-h), which progressively turn into forms with a blunted posterior extremity until whole differentiation into bell-shaped flagellates with long free flagella (Fig. 7f,g,k), which correspond to the apparently 'rounded' metacyclic trypomastigotes observed by light microscopy (Fig. 7c,d).

Log phase epimastigotes from Hi5-cultures were seeded into monolayers of mammalian LLC-MK2 cells, incubated at $37{ }^{\circ} \mathrm{C}$ with $5 \% \mathrm{CO}_{2}$, and after one to 5 days, cultures were examined by light microscopy of Giemsa-stained flagellates (Fig. 8a-f) and SEM (Fig. 8 g-j). In the supernatant of these cultures, slender epimastigotes gradually became wider (Fig. 8a,g - one day culture) and gave origin to large and wide transition forms (indicated by arrow heads) between epi- and trypomastigotes initially exhibiting wide bodies (Fig. 8b,c,h), and then becoming long and slender showing well-developed undulant membranes and pointed posterior ends (Fig. 8 e,f,i,j). Both large epi- and trypomastigotes are multiplicative forms (Fig. $8 b, d)$. Long and slender forms with sharpened posterior ends and prominent undulant membranes (Fig. 8 e,f,i,j) resemble those present in early haemocultures (Fig. 2) as well as blood trypomastigotes of $T$. theileri of cattle and $T$. theileri -like of water buffalo $[6,21,23,53,63]$ and $T$. cervi and $T$. cervi-like $[2,6,10,38,64]$. Intracellular rounded flagellates resembling 'amastigotes' [65] could be observed inside mammalian cells (data not shown), but unquestionable demonstration of their intracellular development and differentiation requires further studies.

Taken together, cultures of $T$. perronei sp. n. showed large epi- and trypomastigotes typical of Megatrypanum trypanosomes present in both early haemocultures and mammalian cell cultures (Figs 2, $8)$, similar to previously reported in deer blood $[2,6,10,38,64]$. In addition, clumps of small rounded forms and epimastigotes detected in early co-cultures of T. perronei sp. n. in insect cell (Fig. 7) were quite similar to in guts of deer keds infected with T. (Megatrypanum) spp. [38], allowing for inferences about the morphological differentiation through the life cycle of T. perronei sp. $\mathrm{n}$. in vertebrate hosts and putative vectors according to the predicted life cycle (Fig. 2). Before T. perronei sp. n., culture of one deer Megatrypanum trypanosome was obtained only for T. cervi of elk from the USA [28]. Morphological comparison of T. perronei sp. n. blood trypomastigotes and epimastigotes from vector guts with corresponding forms of previously reported deer trypanosomes did not revealed species-specific features, thus corroborating the high morphological resemblance of all Megatrypanum trypanosomes $[2,6,10,21,38,64]$.

\section{Ultrastructural characterization of Trypanosoma perronei sp. $\mathbf{n}$.}

Transmission electron microscopy (TEM) of cultured T. perronei sp. n. revealed mitochondrion, Golgi, glycosomes, acidocalcisomes, flagellum and overall ultrastructural organization typical of trypanosomes. A set of features can be considered common of Megatrypanum trypanosomes: An abundance of acidocalcisomes (Fig. 9a,b) distributed throughout the cell body; a kinetoplast exhibiting long and weakly compacted DNA fibrils and, consequently, wide thickness (Fig. 9a-d), a noticeable spongiome comprising 
a network of tubules and contractile vacuoles near the flagellar pocket (Fig. 9c,e,f), and the absence of cytostome. This is the first time that a deer trypanosome is characterized by TEM, and the ultra-structural arrangement was similar to that showed previously for $T$. theileri $[23,65]$.

\section{Taxonomical summary}

Phylum Euglenozoa (Cavalier-Smith, 1981); Class Kinetoplastea (Honigberg, 1963); Order Trypanosomatida (Kent, 1880; Hollande, 1982); Family Trypanosomatidae (Doflein, 1951); Genus Trypanosoma (Gruby, 1843);

\section{New species description}

Trypanosoma perronei sp. n. Teixeira, Camargo and García

Type material: Hapantotype, culture of the isolate TCC2268. The isolate WTD A3, known just by partial ITS rDNA and SSU rRNA sequences obtained from the blood of WTD from USA, and deposited in GenBank as Trypanosoma sp. PJH-2013a isolate WTD A3, was herein designed as a genotype of $T$. perroneisp. $\mathrm{n}$.

Vertebrate host: Odocoileus virginianus (Ruminantia, Cervidae).

Invertebrate hosts (putative vectors):Lipoptena mazamae (deer ked).

Habitats: the blood of WTD and the digestive tract of deer keds. Type locality: State of Anzoátegui, Venezuela (N1007'08.95", W64³8'23.80'), South America.

Morphology: Log-phase epimastigotes co-cultured with Hi-5 insect cells with bodies averaging $21.61 \pm 9.11 \mu \mathrm{m}$ long and $2.35 \pm 1.03 \mu \mathrm{m}$ wide (Fig. 7). Large and slender trypomastigotes of co-cultures with mammalian cells showing bodies averaging $11.13 \pm 2.86 \mu \mathrm{m}$ long and $1.73 \pm 0.29 \mu \mathrm{m}$ wide, conspicuous undulant membranes and long free flagella (Fig. 8).

Moleculardiagnosis: DNA sequences unique to T. perronei sp. n. deposited in GenBank under the following accession numbers: SSU rRNA (MN752212), V7V8SSU rRNA (MN752143), gGAPDH (MN756794), ITS1 rDNA (MN752208-MN752209), and CatL (MN747149-MN747155).

Species depository: Culture of T. perronei sp. $\mathrm{n}$. is cryopreserved at the Trypanosomatid Culture Collection of the University of São Paulo, TCC-USP, which also includes Giemsa-stained smears of cultures in glass slides, and DNA samples from cultures, blood of infected WTD and gut contents of deer keds.

ZooBank registration: To comply with the regulations of the amended 2012 version of the International Code of Zoological Nomenclature (ICZN) [66], T. perronei sp. n. was registered in ZooBank, the online registration system for the ICZN, under the Life Science Identifier (LSID):

urn:Isid:zoobank.org:act:22747D46-AD0F-4013-B2D0-2F51080CFD54. 
Etymology: The name "perronei" was given as a tribute to Dr. Trina Mercedes Perrone Carmona, a Venezuelan biologist who contributed to the knowledge of animal trypanosomiasis and the progress of the veterinary sciences in Venezuela, and who died unexpectedly in 2008.

Remarks: Recent phylogenies have unveiled more than one trypanosome species infecting the PanAmerican WTD (O. virginianus). Besides T. perronei sp. $\mathrm{n}$. of the Tthll lineage detected in WTD from Venezuela and USA, this species of deer was reported as hosts of a trypanosome of the Tthl lineage, so far only detected by PCR in WTD and elks [12]. Elks are hosts of the T. cervi and, apparently, can also harbour other trypanosomes, but so far were not found infected with T. perronei sp. $\mathrm{n}$. The only trypanosome reported in a deer species endemic to South America is T. mazamarum, described in blood of the brocket deer in Argentina [19], and never cultivated or molecularly characterized.

\section{Conclusions}

In the present study, we combined molecular, morphological, culture behaviour, biological and phylogeographical data to describe T. perronei sp. n. detected in WTD blood and keds. Phylogeographical histories of cervids and respective trypanosomes from this and previous studies support historical dispersion of cervids and co-migrating Megatrypanum trypanosomes. Altogether, deer-trypanosomevector associations and phylogeography support a plausible evolutionary scenario where WTD infected with the ancestor of T. perronei, likely infested by its tightly linked ectoparasite L. mazamae, were introduced from North America into South America through the Panama Isthmus. This scenario is strongly reinforced by the discovery of recently diversified geographical variants of the Pan-American T. perronei sp. $\mathrm{n}$. in the USA and Venezuela, compatible with the introduction of T. perronei sp. $\mathrm{n}$. with the recent invasion of South America by WTD from North America at the Pliocene-Pleistocene boundary. Underestimated genetic repertoire and entangled relationships of morphologically indistinguishable trypanosomes from cervids and bovids point to the need for more comprehensive surveys to assess species richness, and host-parasite-vector associations of Megatrypanum trypanosomes.

\section{Declarations}

\section{Acknowledgments}

We are thankful to "Empresas Polar", Barcelona, state of Anzoátegui in Venezuela for authorization, logistic support and help in deer management. The authors would like to thank CE Jared and MM Antoniazzi for the access to electron microscopic facilities of the Institute Butantan, Brazil.

Funding: This study received financial support through Brazilian grants from the PROSUL program (CNPq) and FAPESP (Process $\mathrm{n}-2016 / 07487-0$ ). CMFR and HAG are postdoctoral fellows of CNPq (INCTEpiAmo) and FAPESP (Process no 2016/03028-1), respectively.

\section{Availability of data and materials}


Cultured flagellates cryopreserved and in glass slides, and DNA samples of Trypanosoma perronei sp. $\mathrm{n}$. are deposited at the Trypanosomatid Culture Collection of the University of São Paulo, Brazil. The newly determined DNA sequences were all deposited in the GenBank under the accession numbers MN752212 (SSU rRNA), MN752143 (V7V8SSU rRNA), MN756794 (gGAPDH), MN752208-MN752209 (ITS1 rDNA), and MN747149-MN747155 (CATL gene).

\section{Authors' contributions}

HAG, MMGT and EPC conceived and supported the study. HAG, CMFR and APBM designed and coordinated field and laboratory work. HAG and APBM performed the fieldwork in Venezuela and participated in parasite isolation and morphological analysis. HAG, CMFR and ACR were responsible for the molecular diagnosis and phylogenetic analyses. MC carried out culturing, behavioural and morphological analyses. CSAT performed electron microscopic analyses. HAG, MMGT and EPC wrote the manuscript. All authors contributed to the revisions of the manuscript, read and approved the final manuscript.

\section{Ethics approval and consent to participate}

All field procedures and deer handling were performed in accordance with the protocol approved by the MINEC (the Venezuelan Ministerio del Poder Popular para el Ecosocialismo) permit Number 2013154125.

\section{Consent for publication}

Not applicable.

\section{Competing interests}

The authors declare that they have no competing interests.

\section{References}

1. Heckeberg NS, Erpenbeck D, Wörheide G, Rössner GE. Systematic relationships of five newly sequenced cervid species. PeerJ. 2016;4:e2307. doi:10.7717/peerj.2307.

2. Lefebvre MF, Semalulu SS, Oatway AE, Nolan JW. Trypanosomiasis in woodland caribou of northern Alberta. J Wildl Dis. 1997;33:271-7.

3. Kutz SJ, Ducrocq J, Verocai GG, Hoar BM, Colwell DD, Beckmen KB, et al. Parasites in ungulates of Arctic North America and Greenland: a view of contemporary diversity, ecology, and impact in a world under change. Adv Parasitol. 2012;79:99-252. doi: 10.1016/B978-0-12-398457-9.00002-0.

4. Kingston N, Drozdz J, Rutkowska M. Trypanosoma spp. in red deer (Cervuselaphus) and elk (Alcesalces) in Poland. Proc Helminthol Soc Wash. 1985a;52:144-5. 
5. Morton JK, Kingston N. Further studies on trypanosomes in game animals in Wyoming. J Wildl Dis. 1976;12:233-6.

6. Hoffmann M, Büscher G, Friedhoff KT. Stercorarian trypanosomes from deer (Cervidae) in Germany. J Protozool. 1984;31:581-4.

7. Kingston N, Bobek B. A trypanosome in roe deer, Capreoluscapreolus, in southern Poland. Proc Helminthol Soc Wash. 1985;52:143.

8. Kingston N, Morton JK, Dieterich R. Trypanosomacervi from Alaskan reindeer, Rangifertarandus. J Protozool. 1982;29:588-91.

9. Matthews MJ, Kingston N, Morton JK. Trypanosomacervi Kingston and Morton, 1975 from mule deer, Odocoileushemionus, in Wyoming. J Wildl Dis. 1977;13:33-9.

10. Kingston N, Franzmann A, Maki L. Redescription of Trypanosomacervi (Protozoa) in moose, Alcesalces, from Alaska and Wyoming. Proc Helminthol Soc Wash. 1985b;52:54-9.

11. Telford SR, Forrester DJ, Wright SD, Roelke ME, Ferenc SA, McCown JW. The identity and prevalence of Trypanosoma in white-tailed deer (Odocoileusvirginianus) from South Florida. J Helminthol Soc Wash. 1991;58:19-23.

12. Fisher AC, Schuster G, Cobb WJ, James AM, Cooper SM, Peréz de León AA, et al. Molecular characterization of Trypanosoma (Megatrypanum) spp. infecting cattle (Bostaurus), white-tailed deer (Odocoileusvirginianus), and elk (Cervus elaphus canadensis) in the United States. Vet Parasitol. 2013;197:29-42. doi:10.1016/j.vetpar.2013.04.037.

13. Dirie MF, Bornstein S, Wallbanks KR, Molyneux DH, Steen M. Comparative studies on Megatrypanum trypanosomes from cervids. Trop Med Parasitol. 1990;41:198-202.

14. Kingston N, Bobek B, Perzanowski K, Wita I, Maki L. Description of Trypanosoma (Megatrypanum) stefanskii sp. n. from roe deer (Capreoluscapreolus) in Poland. J. Helminthol. Soc. Wash. 1992;59:89-95.

15. Martinković F, Matanović K, Rodrigues AC, Garcia HA, Teixeira MMG. Trypanosoma (Megatrypanum) melophagium in the sheep ked Melophagusovinus from organic farms in Croatia: phylogenetic inferences support restriction to sheep and sheep keds and close relationship with trypanosomes from other ruminant species. J Eukaryot Microbiol. 2012:59:134-44. doi:10.1111/j.15507408.2011.00599.x.

16. Hatama S, Shibahara T, Suzuki M, Kadota K, Uchida I, Kanno T. Isolation of a Megatrypanum trypanosome from sika deer (Cervus nippon yesoensis) in Japan. Vet Parasitol. 2007;149:56-64.

17. D'Alessandro A, Wells EA. Trypanosome infections in the family Cervidae. Trans R Soc Trop Med Hyg. 1971;65:845-6.

18. Ayala SC, DAlessandro A, Mackenzie R, Angel D. Hemoparasite infections in wild animals from the eastem Ilanos of Colombia. J Parasitol. 1973;59:52-9.

19. Mazza S, Romana C, Fiora A. Algunos hemoparásitos de mamíferos del Norte. VII. Reunion Soc Argent Patol Reg Norte. 1932;2:990-7. 
20. Deane LM. Tripanosomideos de mamíferos da região Amazônica. I. Alguns flagelados encontrados no sangue de mamíferos silvestres do Estado do Pará. Rev Inst Med Trop S Paulo. 1961;3:15-28.

21. Hoare CA. The Trypanosomes of Mammals: A Zoological Monograph. Blackwell Scientific Publications, Oxford, pp. 1972;123-141.

22. Böse R, Friedhoff KT, Olbrich S, Büscher G, Domeyer I. Transmission of Trypanosomatheileri to cattle by Tabanidae. Parasitol Res. 1987a;73:421-4.

23. Rodrigues AC, Campaner M, Takata CS, Dell'Porto A, Milder RV, Takeda GF, et al. Brazilian isolates of Trypanosoma (Megatrypanum) theileri. diagnosis and differentiation of isolates from cattle and water buffalo based on biological characteristics and randomly amplified DNA sequences. Vet Parasitol. 2003;116:185-207.

24. Rodrigues AC, Paiva F, Campaner M, Stevens JR, Noyes HA, Teixeira MMG. Phylogeny of Trypanosoma (Megatrypanum) theileri and related trypanosomes reveals lineages of isolates associated with artiodactyl hosts diverging on SSU and ITS ribosomal sequences. Parasitology. 2006;132:215-24.

25. Garcia HA, Rodrigues AC, Martinković F, Minervino AH, Campaner M, Nunes VL, et al. Multilocus phylogeographical analysis of Trypanosoma (Megatrypanum) genotypes from sympatric cattle and water buffalo populations supports evolutionary host constraint and close phylogenetic relationships with genotypes found in other ruminants. Int J Parasitol. 2011a;41:1385-96. doi:10.1016/j.jppara.2011.09.001.

26. Ramírez JD, Tapia-Calle G, Muñoz-Cruz G, Poveda C, Rendón LM, Hincapié E, et al. Trypanosome species in neo-tropical bats: biological, evolutionary and epidemiological implications. Infect Genet Evol. 2014;22:250-6. doi: 10.1016/j.meegid.2013.06.022.

27. Jirků M, Votýpka J, Petrželková KJ, Jirků-Pomajbíková K, Kriegová E, Vodička R, et al. Wild chimpanzees are infected by Trypanosoma brucei. Int J Parasitol Parasites Wildl. 2015;4:277-82. doi: 10.1016/j.jppaw.2015.05.001.

28. Kingston N, Morton JK. Trypanosomacervisp. n. from elk (Cervuscanadensis) in Wyoming. J Parasitol. 1975;61:17-23.

29. Werszko J, Szewczyk T, Steiner-Bogdaszewska Ż, Wróblewski P, Karbowiak G, Laskowski Z. Molecular detection of Megatrypanum trypanosomes in tabanid flies. Med Vet Entomol. 2019. doi:10.1111/mve.12409.

30. Krinsky WL, Pechuman LL. Trypanosomes in horse flies and deer flies in central New York State. J Parasitol. 1975;61:12-6.

31. Ganyukova Al, Zolotarev AV, Malysheva MN, Frolov AO. First record of Trypanosomatheileri-like flagellates in horseflies from Northwest Russia. Protistology. 2018;12:223-30.

32. Clark GG. Trypanosomes from mule deer in New Mexico and Colorado. J Wildl Dis. 1972; 8:325-26.

33. Jaimes-Dueñez J, Triana-Chávez O, Mejía-Jaramillo AM. Spatial-temporal and phylogeographic characterization of Trypanosoma spp. in cattle (Bostaurus) and buffaloes (Bubalusbubalis) reveals 
transmission dynamics of these parasites in Colombia. Vet Parasitol. 2018;249:30-42. doi:10.1016/j.vetpar.2017.11.004.

34. Taioe MO, Motloang MY, Namangala B, Chota A, Molefe NI, Musinguzi SP, et al. Characterization of tabanid flies (Diptera: Tabanidae) in South Africa and Zambia and detection of protozoan parasites they are harbouring. Parasitology. 2017;144:1162-78. doi:10.1017/S0031182017000440.

35. Votýpka J, Rádrová J, Skalický T, Jirků M, Jirsová D, Mihalca AD, et al. A tsetse and tabanid fly survey of African great apes habitats reveals the presence of a novel trypanosome lineage but the absence of Trypanosomabrucei. Int J Parasitol. 2015;45:741-8. doi:10.1016/j.ijpara.2015.06.005.

36. Votýpka J, Brzoňová J, Ježek J, Modrý D. Horse flies (Diptera: Tabanidae) of three West African countries: A faunistic update, barcoding analysis and trypanosome occurrence. Acta Trop. 2019;197:105069. doi:10.1016/j.actatropica.2019.105069.

37. Gibson W, Pilkington JG, Pemberton JM. Trypanosomamelophagium from the sheep ked Melophagusovinus on the island of St Kilda. Parasitology. 2010;137:1799-1804. doi:10.1017/S0031182010000752.

38. Böse R, Petersen K. Lipoptenacervi (Diptera), a potential vector of Megatrypanum trypanosomes of deer (Cervidae). Parasitol Res. 1991;77:723-5.

39. Skvarla MJ, Machtinger ET. Deer Keds (Diptera: Hippoboscidae: Lipoptena and Neolipoptena) in the United States and Canada: New state and county records, pathogen records, and an illustrated key to Species. J Med Entomol. 2019;56:744-760. doi:10.1093/jme/tjy238.

40. Garcia HA, Rodrigues CMF, Rodrigues AC, Pereira DL, Pereira CL, Camargo EP, et al. Remarkable richness of trypanosomes in tsetse flies (Glossina morsitans morsitans and Glossina pallidipes) from the Gorongosa National Park and Niassa National Reserve of Mozambique revealed by fluorescent fragment length barcoding (FFLB). Infect Genet Evol. 2018;63:370-9. doi:10.1016/j.meegid.2017.07.005.

41. Fermino BR, Paiva F, Viola LB, Rodrigues CMF, Garcia HA, Campaner M, et al. Shared species of crocodilian trypanosomes carried by tabanid flies in Africa and South America, including the description of a new species from caimans, Trypanosoma kaiowa n. sp. Parasit Vectors. 2019;12:225. doi:10.1186/s13071-019-3463-2.

42. Rodrigues AC, Garcia HA, Ortiz PA, Cortez AP, Martinković F, Paiva F, et al. Cysteine proteases of Trypanosoma (Megatrypanum) theileri: cathepsin L-like gene sequences as targets for phylogenetic analysis, genotyping diagnosis. Parasitol Int. 2010a;59:318-25. doi:10.1016/j.parint.2010.03.002.

43. Rodrigues AC, Garcia HA, Batista JS, Minervino AH, Góes-Cavalcante G, Maia da Silva F, et al. Characterization of spliced leader genes of Trypanosoma (Megatrypanum) theileri: phylogeographical analysis of Brazilian isolates from cattle supports spatial clustering of genotypes and parity with ribosomal markers. Parasitology. 2010b;137:111-22. doi:10.1017/S0031182009991053.

44. Thompson JD, Higgins DG, Gibson TJ. CLUSTAL W: improving the sensitivity of progressive multiple sequence alignment through sequence weighting, position-specific gap penalties and weight matrix 
choice. Nucleic Acids Res. 1994;11:4673-80.

45. Swofford DL. PAUP*: phylogenetic analysis using parsimony (*and other methods), version 4. Sinauer Associates, Sunderland, Massachusetts, USA. 2002.

46. Stamatakis A. RAxML-VI-HPC: maximum likelihood-based phylogenetic analyses with thousands of taxa and mixed models. Bioinformatics. 2006;22:2688-90.

47. Huelsenbeck JP, Ronquist F. MRBAYES: Bayesian inference of phylogenetic trees. Bioinformatics. 2001;17:754-5.

48. Huson DH, Bryant D. Application of phylogenetic networks in evolutionary studies. Mol Biol Evol. 2006;23:254-67.

49. Lima L, Espinosa-Álvarez O, Hamilton PB, Neves L, Takata CS, Campaner M, et al. Trypanosomalivingstonei: a new species from African bats supports the bat seeding hypothesis for the Trypanosoma cruzi clade. Parasit Vectors. 2013;6:e221. doi:10.1186/1756-3305-6-221.

50. Garcia HA, Kamyingkird K, Rodrigues AC, Jittapalapong S, Teixeira MMG, Desquesnes M. High genetic diversity in field isolates of Trypanosomatheileri assessed by analysis of cathepsin L-like sequences disclosed multiple and new genotypes infecting cattle in Thailand. Vet. Parasitol. 2011b;180:363-7. doi:10.1016/j.vetpar.2011.03.017.

51. Ybañez AP, Sivakumar T, Ybañez RH, Vincoy MR, Tingson JA, Perez ZO, et al. Molecular survey of bovine vector-borne pathogens in Cebu, Philippines. Vet Parasitol. 2013;196:13-20. doi:10.1016/j.vetpar.2013.02.013.

52. Weerasooriya G, Sivakumar T, Lan DT, Long PT, Takemae H, Igarashi I, et al. Epidemiology of bovine hemoprotozoa parasites in cattle and water buffalo in Vietnam. J Vet Med Sci. 2016;78:1361-7. doi:10.1292/jvms.16-0099.

53. Suganuma K, Kondoh D, Sivakumar T, Mizushima D, Elata ATM, Thekisoe OMM, et al. Molecular characterization of a new Trypanosoma (Megatrypanum) theileri isolate supports the two main phylogenetic lineages of this species in Japanese cattle. Parasitol Res. 2019;118:1927-35. doi:10.1007/s00436-019-06313-x.

54. Calzolari M, Rugna G, Clementi E, Carra E, Pinna M, Bergamini F, et al. Isolation of a trypanosome related to Trypanosoma theileri (Kinetoplastea: Trypanosomatidae) from Phlebotomusperfiliewi (Diptera: Psychodidae). Biomed Res Int. 2018;15:e2597074. doi:10.1155/2018/2597074.

55. Lloyd JE. Louse flies, keds, and related flies (Hippoboscoidea), pp. 349-362. In G. Mullen and L. Durden (eds.), Medical and veterinary entomology. Academic Press, San Diego, CA. 2002.

56. Böse R, Friedhoff KT, Olbrich S. Transmission of Megatrypanum trypanosomes to Cervusdama by Tabanidae. J Protozool. 1987b;34:110-3.

57. Böse R, Heister NC. Development of Trypanosoma (M.) theileri in tabanids. J Eukaryot Microbiol. 1993;40:788-92.

58. Schoener E, Uebleis SS, Cuk C, Nawratil M, Obwaller AG, Zechmeister T, et al. Trypanosomatid parasites in Austrian mosquitoes. PLoS One. 2018;13:e0196052. doi:10.1371/journal.pone.0196052. 
59. Böse R, Petersen K, Pospichal H, Buchanan N, Tait A. Characterization of Megatrypanum trypanosomes from European Cervidae. Parasitology. 1993;107:55-61.

60. Gilbert C, Ropiquet A, Hassanin A. Mitochondrial and nuclear phylogenies of Cervidae (Mammalia, Ruminantia): Systematics, morphology, and biogeography. Mol Phylogenet. Evol. 2006;40:101-17. doi:10.1016/j.ympev.2006.02.017.

61. Hoberg EP, Galbreath KE, Cook JA, Kutz SJ, Polley L. Northern host-parasite assemblages: history and biogeography on the borderlands of episodic climate and environmental transition. Adv. Parasitol. 2012;79:1-97. doi:10.1016/B978-0-12-398457-9.00001-9.

62. Asada M, Takeda M, Tomas WM, Pellegrin A, de Oliveira CHS, Barbosa JD, et al. Close relationship of Plasmodium sequences detected from South American pampas deer (Ozotocerosbezoarticus) to Plasmodium spp. in North American white-tailed deer. Int J Parasitol Parasites Wildl. 2018;7:44-7. doi: 10.1016/j.jppaw.2018.01.001.

63. Wells EA. Subgenus Megatrypanum. In: Lumsden, W.H.R., Evans, D.A. (Eds.), Biology of the Kinetoplastida. Academic Press, London. 1976;257-75.

64. Krinsky WL. Trypanosomes from white-tailed deer (Odocoileusvirginianus) in New York. J Parasitol. 1975;61:145-6.

65. Lee YF, Cheng CC, Chen JS, Lin NN, Hung YW, Wang JM, et al. Evidence of intracellular stages in Trypanosoma (Megatrypanum) theileri in non-phagocytic mammalian cells. Vet Parasitol. 2013;191:228-39. doi:10.1016/j.vetpar.2012.08.027.

66. ICZN. International Commission on Zoological Nomenclature: amendment of articles 8, 9, 10, 21 and 78 of the International Code of Zoological Nomenclature to expand and refine methods of publication. Bull Zool Nomencl. 2012;69:161-9.

\section{Figures}




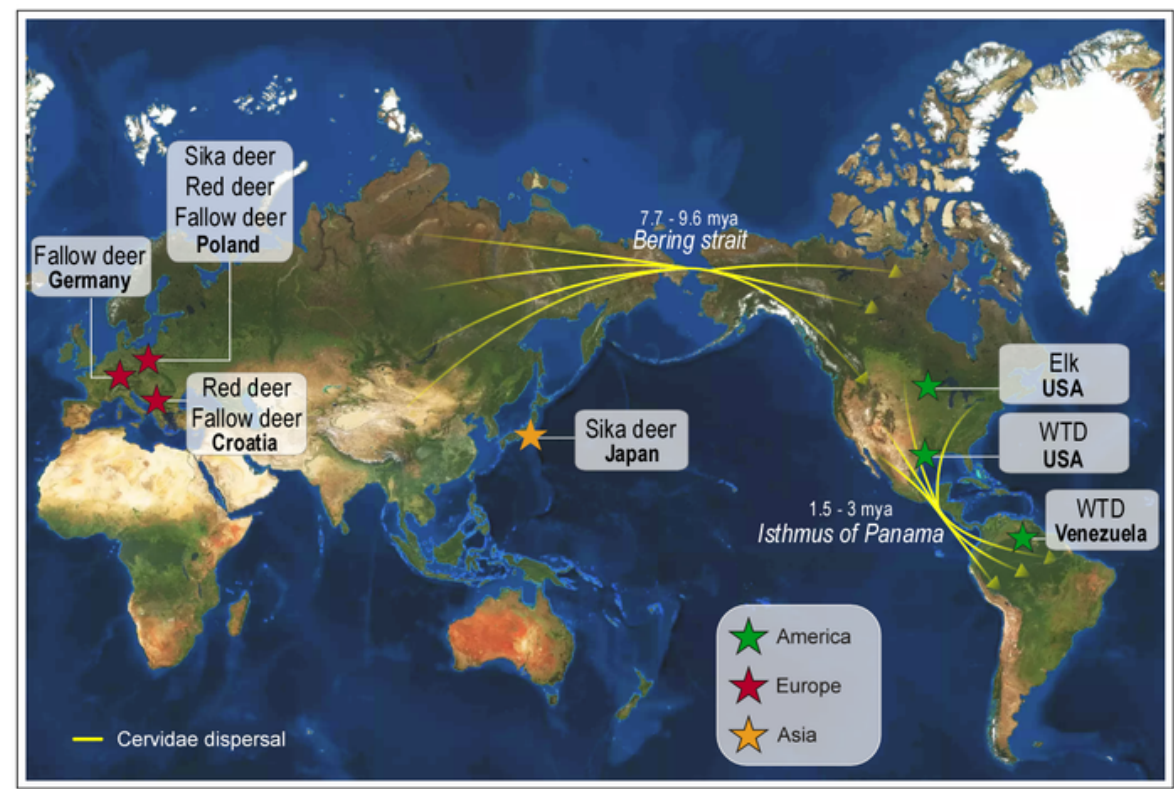

\section{Figure 1}

Origin of Trypanosoma (Megatrypanum) perronei sp. $\mathrm{n}$. and other deer trypanosomes. Geographical origin of deer samples, and historical dispersion of cervids from Eurasia reaching North America through the Bering Strait, and thereafter through the Panama Isthmus into South America. WTD = white-tailed deer (Odocoileus virginianus). 


\section{Figure 2}

Predicted life cycle of Trypanosoma (Megatrypanum) perronei sp. $\mathrm{n}$. in its host Odocoileus virginianus (white-tailed deer) and its putative vector the deer ked Lipoptena mazamae. Morphology and development of T. perronei sp. n. were inferred from (A) early haemocultures and co-cultivation with LLCMK2 mammalian $\left(37^{\circ} \mathrm{C}\right)$ and $(\mathrm{B}) \mathrm{Hi}-5$ insect $\left(25^{\circ} \mathrm{C}\right)$ cells. Deer keds become infected by feeding on deer containing blood trypomastigotes (similar to forms present in early hemocultures and co-cultures with mammalian cells), which, in their digestive tract, transform and multiply as small forms attached to the cells of wall guts giving origin to epimastigotes that multiply and, later, differentiate into metacyclic trypomastigotes. Most likely, metacyclic trypomastigotes present in the faeces of the vectors are transmitted to WTD by bite wound or mucosa, reaching the bloodstream and transforming into trypomastigotes. Illustration of T. perronei sp. n. metacyclogenesis in insect cultures are shown in the Figure 7.

\section{Figure 3}

. Network analysis of cathepsin L (CATL) sequences of Trypanosoma (Megatrypanum) perronei sp. $\mathrm{n}$. from Venezuelan white-tailed deer and respective deer keds. (A), Analysis of Megatrypanum trypanosomes from wild and domestic ruminants evidencing Tthl and Tthll phylogenetic lineages. (B), Analysis restricted to the lineage Tthll positioning T. perronei sp. n. (TCC2268) from Venezuela tightly clustered with trypanosomes found in guts of deer ked taken from WTD. Genealogy was inferred using the Neighbour-Net method with the K2 parameter and nodal support estimated with 500 bootstrap replicates.

\section{Figure 4}

Barcoding of Trypanosoma (Megatrypanum) perronei sp. n. Comparison of V7V8 SSU rRNA barcodes from T. perronei sp. $n$. and trypanosomes of Tthl and Tthll lineages of the subgenus Megatrypanum from cervids (fallow, red and sika deer, WTD and elks) and bovids (water buffalo, cattle, bison and antelopes). Sequences obtained from deer keds, sheep keds, sand flies, tsetse flies and tabanids were also included. Sequences from the distantly related isolates of elk (elk 317) from the USA were placed as a probable new lineage of Megatrypanum. Dendrograms were inferred by Neighbour-joining using the Kimura 2 parameter algorithm, and nodal supports were estimated with 500 bootstrap replicates.

\section{Figure 5}

Phylogenetic positioning of Trypanosoma (Megatrypanum) perronei sp. n. (A), phylogenetic tree based on gGAPDH sequences from Megatrypanum trypanosomes and species of all other major clades of the genus Trypanosoma using trypanosomatids of other genera as outgroups. Major phylogenetic clades 
were collapsed, whereas the clade Megatrypanum was highlighted. (B), Megatrypanum clade showing major Tthl and Tthll lineages both formed by several genotypes. T. perronei sp. n. was assigned to genotype Tthll $\mathrm{H}$, which was sister to Tthll $\mathrm{C}$, which comprised the German T. sp. D30 of fallow deer and the Croatian TC2 of red deer, altogether forming a clade exclusive of deer trypanosomes from South and North America and Europe. An alignment of 690 characters was employed for maximum likelihood (ML) and Bayesian (B) inferences; the numbers at nodes refer to ML/B support values derived from 500 replicates.

\section{Figure 6}

Lineages and genotypes of trypanosomes of the subgenus Megatrypanum inferred using ITS1 rDNA sequences. Network inferred using polymorphic ITS1 rDNA sequences of trypanosomes representative of genotypes identified in cervids (WTD, follow deer, sika deer and elk), bovids (cattle, water buffalo and antelopes), sheep keds, and sand flies. The analysis was carried out using the Neighbour-Net method with K2P parameter, and nodal support estimated with 500 bootstrap replicates. T. perronei sp. $\mathrm{n}$. comprised highly similar isolates TCC2268 from Venezuela and WTD A3 from Texas-USA assigned to the new genotype Tthll $\mathrm{H}$ closest to Tthll C, which comprised the German T. sp. D30 of fallow deer and the Croatian TC2 of red deer, altogether forming a clade exclusive of deer trypanosomes from South and North America and Europe.

\section{Figure 7}

Light and scanning electron microscopy (SEM) of Trypanosoma perronei sp. n. co-cultured with insect cells at $25^{\circ} \mathrm{C}$. Giemsa-stained (a-c) forms of a log-phase ( 5 days) culture (a) exhibiting flagellates adhered by their flagella forming rosettes, and detached epimastigotes. (b) Mid-log (7 days) cultures showing long and thin epimastigotes. (c) Stationary culture (10 days) exhibiting epimastigotes, transition forms between epi- and trypomastigotes (arrow heads), and unique "rounded" metacyclic trypomastigotes. A typical metacyclic was enlarged in (d). SEM of mid-log phase cultures (7 days) showing epimastigotes of variable length and wide (e-j) including forms with well-developed undulant membranes $(f,-j)$, transition forms ( $f-h)$, and bell-shaped metacyclic trypomastigotes $(f, g, k)$. Nucleus $(n)$, kinetoplast (k), flagellum (f), undulating membrane (um), epimastigote $(E)$, trypomastigote $(T)$, metacyclic trypomastigotes $(\mathrm{mT})$. Bars $=10 \mathrm{um}$

\section{Figure 8}

. Light (Giemsa-staining) and Scanning electron microscopy (SEM) of Trypanosoma peronei sp. $\mathrm{n}$. cultured with monolayers of mammalian (LLCMK2) cells at $37^{\circ} \mathrm{C}$. Giemsa-stained (a-f) and SEM (g-j) showing epimastigotes with one day of culture $(a, g)$, and developmental forms present with 5 days of 
culture showing large and wide epi- and trypomastigotes (b-d), flagellates with two nuclei and one kinetoplast $(b, d)$, transition forms between epi- and trypomastigotes $(b, d, e)$ indicated by arrow heads, and slender and pointed trypomastigotes with a well-developed undulating membrane (d-f, $h-j)$. Nucleus (n), kinetoplast (k), flagellum (f), undulating membrane (um), epimastigote $(E)$, trypomastigote $(T)$. Bars = 10um.

\section{Figure 9}

Ultrastructural features of Trypanosoma perronei sp. $\mathrm{n}$. revealed by transmission electron microscopy (TEM). Longitudinal section of epimastigote $(a, c)$ and trypomastigote $(b)$ forms showing many acidocalcisomes $(a, b)$, and kinetoplasts displaying weakly compacted and long DNA fibrils (a-d). Flagellar pocket region showing the spongiome, a network of tubules and large contractile vacuoles (c, e, f). Longitudinal section of a dividing epimastigote exhibiting two flagella, two basal bodies and just one kinetoplast (c). Nucleus (N); kinetoplast (K); flagellum (F); Golgi (G), glycosome (GI), contractile vacuole $(\mathrm{Cv})$, basal body (Bb); acidocalcisomes (Ac); Mitochondria (M); spongiome (Sp). Bars $=0.5 \mathrm{um}$.

\section{Supplementary Files}

This is a list of supplementary files associated with this preprint. Click to download.

- SupplementaryTableS4.doc

- SupplementaryTableS2.doc

- SupplementaryTableS1.doc

- SupplementaryTableS3.doc 